\title{
Suicide after a stroke: a population study
}

\author{
T W Teasdale, A W Engberg
}

\begin{abstract}
Study objective-To establish whether there are increased rates of suicide after a stroke and the degree to which any increase is related to gender, age at stroke, diagnosis, duration of hospitalisation, and time since stroke.

Design-Cross linkage of national registers for hospitalisations and causes of death.
\end{abstract}

Setting-The population of Denmark, 1979-1993.

Patients-A study cohort was defined comprising all 114098 stroke patients discharged alive from hospital during the period 1979-1993. These patients were then screened in a register of causes of death over the same time period, and 359 cases of suicide were identified.

Main results-Annual incidence rates, both observed and expected, together with standardised mortality ratios (SMR) were computed based on annual population and suicide statistics, stratified by age and gender. The overall annual incidence rate of suicide in the cohort was 83 per 100000 per year compared with an expected figure of 45 (difference $=38,95 \% \mathrm{CI}=27$, 49). Correspondingly, SMR were increased for stroke patients. Across all age bands the SMR for mens was 1.88 (95\%CI $1.66,2.13)$ and for women $1.78(1.48,2.14)$. SMR were greatest $(2.85 ; 2.17,3.76)$ for patients under 50 years of age group and were least for patients 80 years or older $(1.3 ; 0.95,1.79)$. There was no clear relation to stroke diagnosis. Suicides were negatively related to duration of hospitalisation, being lowest for those hospitalised for more than three months $(0.88 ; 0.65$, 1.19) and highest for those hospitalised for less than two weeks $(2.32 ; 1.92,2.80)$. Survival analysis suggested that the risk for suicide is greatest up to about five years after a stroke.

Department of Psychology, University of Copenhagen, Njalsgade 88, 2300 Copenhagen S, Denmark

T W Teasdale

Centre for Medicine, Division of Stroke. Hvidovre University

Hospital, Denmark A W Engberg

Correspondence to: Dr Teasdale

(teasdale@psy.ku.dk)

Accepted for publication 30 May 2001

Depressive symptoms and clinical depression are not uncommon among stroke patients and the phenomenon of post-stroke depression is widely recognised..$^{1-3}$ More seriously, suicide ideation and suicide attempts have also been reported. ${ }^{4}$ Because of their relative infrequency however, completed suicides among stroke patients have generally only been reported among single case or small sample studies. ${ }^{5} \mathrm{~A}$ recent exception was a Danish study that reported on 140 suicides occurring among over 37000 stroke patients across a 17 year period in one county of Denmark; measured against population statistics for suicide. Stenager $e t a l^{6}$ found that standardised mortality ratios were markedly increased for stroke patients, particularly among relatively younger patients and among women. The objectives of this study were to attempt to replicate these findings using a full national cohort of stroke patients and to consider the role of stroke morbidity and potential risk periods for suicide after hospital discharge.

\section{Methods}

DATA SOURCES

Participants in this study were identified in a computerised National Bureau of Health Register of Hospitalisations, which documents all somatic hospitalisations in Denmark since 1979, including admission and discharge dates and discharge diagnoses. ${ }^{7}$ As part of a larger study, the register was searched for all cases with a discharge, between the years 1979 and 1993 inclusive, with a diagnosis of stroke. During this time period the International Classification of Diseases 8th edition codes was used in the register. The diagnoses included in this study were grouped as follows: (1) subarachnoid haemorrhage (ICD 430); (2) intracerebral haemorrhage (ICD 431); (3) cerebral ischaemia; precerebral arterial occlusion (ICD 432); cerebral thrombosis (ICD 433); cerebral embolism (ICD 434); (4) undefined-acute but undefined cerebrovascular disease (ICD 436).

The diagnosis of transient cerebral ischaemia (ICD 435) was not included. To eliminate doubtful cases, all diagnoses for which a modification code was appended (for example, "obs-pro." or "sequelae") were excluded, with the single exception of the modification code "operatus". Cases where the discharge diagnoses included epilepsy were likewise excluded because the recorded stroke diagnosis may have referred to an earlier episode, itself contributory to the current epileptic condition. Where more than one of the above diagnoses was recorded at discharge (about $7 \%$ of cases), the case was categorised according to the above order. Patients admitted more than once over the 15 year period are here registered with the first admission.

Patients identified in the hospitalisation register were then screened in a national register of deaths, also for the period up to $1993 .{ }^{8}$ This register records date and cause of death.

The search of the hospitalisation register identified 146807 patients with a stroke diagnosis 
Table 1 Age at stroke, duration of hospitalisation, and deaths and suicides as a function of gender and diagnosis

\begin{tabular}{|c|c|c|c|c|c|}
\hline Gender and diagnosis & Number & $\begin{array}{l}\text { Mean age years } \\
\text { (SD) }\end{array}$ & $\begin{array}{l}\text { Mean hospitalisation } \\
\text { days (SD) }\end{array}$ & $\begin{array}{l}\text { Deaths } \\
\text { (\% of number) }\end{array}$ & $\begin{array}{l}\text { Suicides } \\
\text { (\% of number) }\end{array}$ \\
\hline \multicolumn{6}{|l|}{ Men } \\
\hline Subarachnoid haemorrhage & 2682 & $50.7(15)$ & $40(61)$ & $1137(42)$ & $8(0.3)$ \\
\hline Intracerebral haemorrhage & 5333 & $64.2(14)$ & $61(75)$ & $3199(60)$ & $28(0.5)$ \\
\hline Cerebral ischaemia & 21024 & $66.7(12)$ & $58(71)$ & $11853(56)$ & $100(0.5)$ \\
\hline Undefined & 29230 & $71.4(11)$ & $57(67)$ & $17521(60)$ & $110(0.4)$ \\
\hline \multicolumn{6}{|l|}{ Women } \\
\hline Subarachnoid haemorrhage & 3774 & $52.8(15)$ & $46(68)$ & $1617(43)$ & $11(0.3)$ \\
\hline Intracerebral haemorrhage & 4558 & $69.1(14)$ & $68(81)$ & $2842(62)$ & $10(0.2)$ \\
\hline Cerebral ischaemia & 17920 & $70.7(13)$ & $64(74)$ & $9983(56)$ & $40(0.2)$ \\
\hline Undefined & 29577 & $75.6(11)$ & $65(72)$ & $17931(61)$ & $52(0.2)$ \\
\hline
\end{tabular}

between the years 1979 and 1993 inclusive. Of this number we have excluded the 32254 patients who died in hospital. Furthermore, as this study concerns suicide, which is very rare among children, we have also excluded the 455 children who were under 15 years at the time of admission. The present sample thus comprises 114098 patients.

The distribution of age and hospitalisation duration for the sample as a function of gender and diagnosis grouping is shown in table 1. As is typical among stroke patients, the subarachnoid haemorrhage patients were younger, more often female, and hospitalised for a shorter time, than patients in the other three diagnostics groups. Table 1 also shows the total numbers of deaths and the numbers of suicides during the study period.

The occurrence of "undefined" diagnoses (ICD 436) was strongly related to age, comprising $22 \%$ among patients younger than 50 and $67 \%$ of patients aged 80 or older.

STANDARDISED MORTALITY RATIOS (SMR)

These ratios were computed against published statistics for the total Danish population alive on 1 January of each year between 1979 to 1993 and the annual numbers of suicides for each of these years. Both population totals and numbers of suicides for each year were stratified by gender and age bands. It is important to note that the computations thus took account of the declining suicide rate in Denmark that has been noted elsewhere ${ }^{9}$ and that parallels the secular trends recently reported for England and Wales. ${ }^{10}$

\section{Results}

Table 2 shows the SMR as a function of gender, age at stroke, diagnostic group, and duration of hospitalisation. Suicides were relatively more common among men $(0.42 \%)$ than among women $(0.20 \%)$, this difference being statistically significant $\left(\chi^{2}(1)=43.9, p<0.001\right)$. However, as can be seen, this discrepancy conforms to the population base rate and there is no difference between the SMR values for men and women, both values being approximately 1.8 overall.

Almost $60 \%$ (214) of suicides occurred when the patient was over 65 years old. However, for age at stroke there is an almost uniform decrease in the SMR with increasing age. For patients suffering a stroke before the age of 50 the SMR indicate that there is almost a threefold excess of suicides relative to the base population. For patients suffering a stroke at age 80 or over the SMR is not significantly above unity.

Among the diagnostic groups, the intracerebral haemorrhage patients have a somewhat higher SMR than the other three groups, which do not differ among themselves. There is, however, substantial overlap in the confidence intervals for all diagnostic groups.

Duration of hospitalisation seems to be negatively associated with suicide risk. The SMR being highest for those hospitalised for less than one month and in fact falling below unity for those hospitalised for more than three months. It should be noted that there is only a weak correlation between age at stroke and duration of hospitalisation (Spearman's $\rho=$ $0.14)$ and the effects of age and hospitalisation

Table 2 Standardised mortality ratios for suicide as a function of gender, age at stroke, diagnosis and duration of hospitalisation

\begin{tabular}{|c|c|c|c|c|c|c|}
\hline & $\begin{array}{l}\text { Number of } \\
\text { cases }\end{array}$ & $\begin{array}{l}\text { Observed } \\
\text { years }\end{array}$ & $\begin{array}{l}\text { Observed } \\
\text { frequency }\end{array}$ & $\begin{array}{l}\text { Expected } \\
\text { frequency }\end{array}$ & $\begin{array}{l}\text { Standardised } \\
\text { mortality ratio }\end{array}$ & $\begin{array}{l}95 \% \text { Confidence } \\
\text { intervals }\end{array}$ \\
\hline \multicolumn{7}{|l|}{ Gender } \\
\hline Male & 58269 & 220425 & 246 & 130.92 & 1.88 & $1.66,2.13$ \\
\hline Female & 55829 & 210328 & 113 & 63.57 & 1.78 & $1.48,2.14$ \\
\hline \multicolumn{7}{|l|}{ Age at stroke } \\
\hline $15-49$ & 8972 & 49545 & 51 & 17.87 & 2.85 & $2.17,3.76$ \\
\hline $50-59$ & 12500 & 64670 & 66 & 29.64 & 2.23 & $1.75,2.83$ \\
\hline $60-69$ & 25556 & 115175 & 88 & 53.59 & 1.64 & $1.33,2.02$ \\
\hline $70-79$ & 39127 & 135122 & 115 & 63.48 & 1.81 & $1.51,2.17$ \\
\hline $80+$ & 27943 & 66240 & 39 & 29.90 & 1.30 & $0.95,1.79$ \\
\hline \multicolumn{7}{|l|}{ Diagnosis } \\
\hline Subarachnoid haemorrhage & 6456 & 28057 & 19 & 10.38 & 1.83 & $1.17,2.87$ \\
\hline Intracerebral haemorrhage & 9891 & 33089 & 38 & 14.59 & 2.60 & $1.90,3.58$ \\
\hline Cerebral ischaemia & 38944 & 172785 & 140 & 79.11 & 1.77 & $1.50,2.09$ \\
\hline Undefined & 58807 & 196822 & 162 & 90.40 & 1.79 & $1.54,2.09$ \\
\hline \multicolumn{7}{|l|}{ Duration of hospitalisation } \\
\hline$<2$ weeks & 29923 & 101052 & 107 & 46.22 & 2.32 & $1.92,2.80$ \\
\hline $2-4$ weeks & 24324 & 96534 & 100 & 43.29 & 2.31 & $1.90,2.81$ \\
\hline 1-3 months & 34553 & 126996 & 110 & 57.29 & 1.92 & $1.59,2.31$ \\
\hline$>3$ months & 25298 & 106171 & 42 & 47.68 & 0.88 & $0.65,1.19$ \\
\hline
\end{tabular}


Table 3 Cox regression analysis-hazard ratios

\begin{tabular}{|c|c|c|c|c|c|}
\hline & Wald & $d f$ & $p$ & $\begin{array}{l}\text { Hazard } \\
\text { ratio }\end{array}$ & $\begin{array}{l}95 \% \text { Confidence } \\
\text { intervals }\end{array}$ \\
\hline Gender & 31.3 & 1 & $<0.001$ & 1.91 & $1.52,2.40$ \\
\hline Age at stroke ${ }^{\star}$ & 10.3 & 4 & 0.04 & & \\
\hline $15-49$ & & & & 1.84 & $1.18,2.87$ \\
\hline $50-59$ & & & & 1.70 & $1.13,2.57$ \\
\hline $60-69$ & & & & 1.27 & $0.86,1.87$ \\
\hline $70-79$ & & & & 1.46 & $1.01,2.10$ \\
\hline Diagnosis & 5.80 & 3 & 0.12 & & \\
\hline Duration of hospitalisation $\uparrow$ & 29.25 & 3 & $<0.001$ & & \\
\hline$<2$ weeks & & & & 2.48 & $1.73,3.55$ \\
\hline $2-4$ weeks & & & & 2.54 & $1.77,3.65$ \\
\hline 1-3 months & & & & 2.19 & $1.53,3.12$ \\
\hline
\end{tabular}

${ }^{\star}$ Hazard ratios relative to age group $=80+. \dagger$ Hazard ratios relative to duration of hospitalisation $=$ $>3$ months.

duration observed here are probably independent of each other. The additivity of the two effects is shown among 3428 patients who suffered a stroke before age 50 and who were hospitalised for less than two weeks. Within this group there were 17 suicides, yielding a SMR of $3.40(95 \%$ CI $2.11,5.47)$.

To examine the role of time since stroke we performed a Cox proportional hazards analysis. ${ }^{11}$ In this analysis all 114098 patients were included, and cases were either observed until suicide $(n=359)$ or were censored at death from other causes $(n=65724)$ or as being alive at the end of the study period-1 January 1994 $(n=48015)$. Gender, age at stroke (grouped as shown in table 2), diagnosis, and duration of hospitalisation (grouped as shown in table 2) were all included as predictors. The computed hazard ratios are shown in table 3.

The highly significant hazard ratio for gender $(p<0.001)$ confirms the approximately doubled greater risk of suicide among men than among women. The effect of age was also significant $(p=0.04)$. Against a baseline of the group of patients of age 80 or older, the hazard ratios for all younger groups were significantly above unity with the exception of those aged between 60 and 69. There was no significant effect of diagnosis group ( $p>0.1)$. Within the groupings of duration of hospitalisation, patients hospitalised for more than three months had significantly lower hazard ratios than all three other groups. Figure 1 shows the overall cumulative proportional hazard over the maximum of 15 years covered by our study. For purposes of illustration the best fitting linear regression line has been superimposed. It can be seen that the function deviates from linearity. The negative acceleration indicates a relative concentration of suicides at under six years after a stroke.

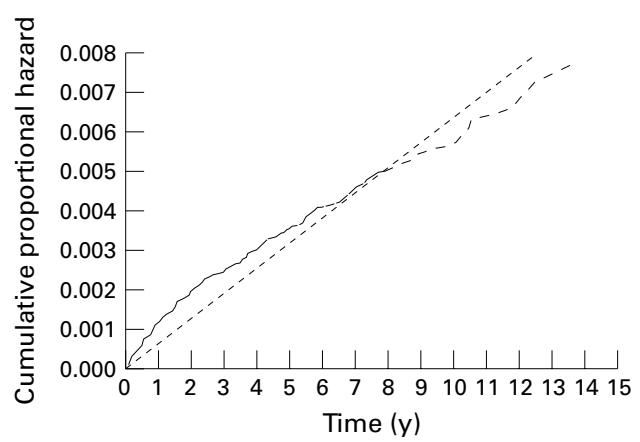

Figure 1 Cumulative proportional hazard for suicide. A linear regression line is superimposed on the function.
KEY POINTS

- There is increased risk of suicide after a stroke.

- The risk seems to be greatest among younger patients and relatively less severe cases.

- The risk seems to be greatest within the first five years after the stroke.

\section{Discussion}

Although this study is both large scale and nationally representative there are a number of limitations that must be considered in the interpretation of the results. Firstly, although the diagnosis of stroke as recorded in the national hospitalisation register can be considered to be reliable, over $50 \%$ of the diagnoses were of undefined subtype. The age and sex distribution of these cases makes it probable that the large majority were ischaemic rather than haemorrhage, but at many smaller hospitals during the time period of the study neuroradiological investigations were not routinely performed, particularly for older patients. A recent study has, however, pointed to an apparent absence of relation between type of stroke and post-stroke depression. ${ }^{12}$ A related limitation of our register data is the lack of data on laterality of stroke. There have been a number of reports that post-stroke depression is more common in cases of left hemisphere stroke than right hemisphere. ${ }^{13}{ }^{14}$ However, a recent comprehensive review of all relevant studies found no support for this assertion. ${ }^{15}$

It is often pointed out that the recording of suicide as a cause of death may be unreliable and under-reported. This is, in part, because it may in some circumstances be difficult to ascertain whether a death was a suicide or an accident, and given any uncertainty there may be a further unwillingness on the part of the relevant medical authority to conclude that death was caused by suicide, especially where there is strong religious disapprobation of suicide. ${ }^{16}{ }^{17}$ There is, however, some evidence to suggest that these effects upon suicide statistics are, in fact, modest. ${ }^{18}$ Certainly it seems likely, however, that such factors would operate less in Denmark than in many other countries. Furthermore, there is no reason to expect that any bias that may be operating would differentially effect the recording of suicides among people who had earlier suffered a stroke, relative to the recording of suicides in the general population. Thus there would be no systematic bias in the mortality ratios as we are reporting them here.

In this study suicides occurred more often among men than among women and were more common among older rather than younger patients. Both of these characteristics are, however, in keeping with international epidemiological evidence for general populations ${ }^{18}$ including Denmark. ${ }^{9}$ Population suicide rates in Denmark are close to figures reported for Western Europe and somewhat higher than those reported for North America. ${ }^{19}$ 
Our major specific finding is that the SMR for post-stroke patients are clearly increased relative to the general Danish population. This generally confirms the earlier findings of Stenager $e t a l^{6}$ for a single county in Denmark. It should however, be noted that the earlier study reported ratios much higher than were found here, particularly for ages below 60 . For women under 60 years of age, a ratio of almost 14 was found, and for men under 60 the ratio was about 6 . By contrast, we have found no difference in ratios between men and women, and the ratios for ages below 60 were under 3 . It is difficult to attribute this anomaly to anything other than sampling fluctuation.

The overall trend in both the present and earlier studies was, however, similar, with ratios being higher for younger ages. This suggests that the disabilities consequent upon a stroke are more disturbing for younger patients than for older ones, as they would entail a greater change in life style with, for instance, the loss of ability to work. This is also consistent with the greater risk of post-stroke depression at younger ages. ${ }^{3}$

The effect of duration of hospitalisation is somewhat paradoxical, in that the risk of suicide decreases with duration of hospitalisation, indicating that increased stroke morbidity reduced the suicide risk. This may come about because the increased handicaps associated with more severe stroke reduce the capacity to carry out so decisive an action as suicide. Such an interpretation would be consistent with a reported positive association between level of functioning and suicide risk in spinal cord injury patients. ${ }^{20}$

The present evidence points to suicide risk being greatest within about the first five years after a stroke. This finding contrasts with that from a parallel study we have conducted on suicide after traumatic brain injury ${ }^{21}$ where suicide risk seemed to be relatively constant across the same 15 year period. The difference may have come about because suicides among traumatic brain injury patients are to some extent related to risk factors for the injury, for example, alcohol misuse, rather than the injury itself. In such cases suicide might be expected to be chronologically independent of the injury. In the present case there is little reason to expect that risk factors for stroke may also be risk factors for suicide, and the suicide is more likely to be reactive to the stroke and its consequences. It would seem, in keeping with findings concerning post-stroke depression, ${ }^{322}$ that the risk decreases with increasing years after stroke.

Although we have here emphasised the role of psychosocial consequences of stroke as causally implicated in the increased risks for suicide this should not be taken to discount possible neurochemical factors. A body of research has implicated the role of serotonergic dysfunction and also abnormalities of cortisol secretion in post-stroke depression. ${ }^{3}$

In summary it should be underlined that although the numbers of suicides in this study is comparatively low, the clearly increased rates relative to the age and gender matched population serve to underline the clinical need, as has been pointed out earlier, ${ }^{6}$ to be sensitive to the potential development of severe adverse emotional reactions to stroke. On present evidence, this is so particularly in relatively young patients, particularly in patients hospitalised for relatively shorter periods, and particularly in the first few years after the illness.

This work was completed while the first author was at the MRC Cognition and Brain Sciences Unit, Cambridge, UK.

Funding: Danish Ministry of Social Services and the Inge Lehmann Foundation.

Conflicts of interest: None.

1 Gordon WA, Hibbard MR. Poststroke depression: an examination of the literature. Arch Phys Med Rehabil 1997;78:658-63.

2 Beekman AT, Penninx BW, Deeg DJ, et al. Depression in survivor of stroke: a community-based study of prevalence, risk factors and consequences. Soc Psychiatry Psychiatr Epidemiol 1998;33:463-70.

3 Robinson RG. Neuropsychiatric consequences of stroke. Annu Rev Med 1997;48:217-29.

4 Kishi Y, Kosier JT, Robinson RG. Suicidal plans in patients with acute stroke. $\mathcal{F}$ Nerv Ment Dis 1996;184:274-80

5 Garden FH, Garrison SJ, Jain A. Assessing suicide risk in stroke patients: review of two cases. Arch Phys Med Rehabil 1990;71:1003-5.

6 Stenager EN, Madsen C, Stenager E, et al. Suicide in patients with stroke: epidemiological study. BMF 1998;316: 1206.

7 Andersen TF, Madsen M, Jorgensen J, et al. The Danish National Hospital Register. A valuable source of data for modern health sciences. Dan Med Bull 1999;46:263-8.

8 Juel K,. Helweg-Larsen K. The Danish registers of causes of Juel K,. Helweg-Larsen K. The Danish
death. Dan Med Bull 1999;46:354-7.

9 Møller-Hansen K..Ingerslev O. Dødsårsagersregisteret 1997. Nye Tal fra Sundhedsstyrelsen 1999;3:1-63.

10 McClure GM. Changes in suicide in England and Wales, 1960-1997. Br F Psychiatry 2000;176:64-7.

11 Parmar MKB, Machin D. Survival analysis: a practical approach. Chichester: Wiley, 1995.

12 Kim JS,.Choi-Kwon S. Poststroke depression and emotional incontinence: correlation with lesion location. Neurology 2000;54:1805-10.

13 Morris PL, Robinson RG, Raphael B, et al. Lesion location and poststroke depression. F Neuropsychiatry Clin Neurosci 1996;8:399-403.

14 Paradiso S, Robinson RG. Minor depression after stroke: an initial validation of the DSM-IV construct. Am $\mathcal{F}$ Geriatr

15 Carson AJ, MacHale S, Allen K, et al. Depression after stroke and lesion location: a systematic review. Lancet 2000;356:122-6

16 Neeleman J, Lewis G. Suicide, religion, and socioeconomic conditions. An ecological study in 26 countries, 1990. 7 Epidemiol Community Health 1999;53:204-10.

17 Neeleman J, Halpern D, Leon D, et al. Tolerance of suicide, religion and suicide rates: an ecological and individual study in 19 Western countries. Psychol Med 1997;27:116571 .

18 Moscicki EK. Identification of suicide risk factors using epidemiologic studies. Psychiatr Clin North Am 1997;20:499517.

19 Schmidtke A, Weinacker B, Apter A, et al. Suicide rates in the world: update. Archives of Suicide Research 1999;5:81-9.

20 Hartkopp A, Bronnum-Hansen H, Seidenschnur AM, et al. Suicide in a spinal cord injured population: its relation to functional status. Arch Phys Med Rehabil 1998;79:1356-61. injury: a population study. $\mathcal{F}$ Neurol Neurosurg Psychiatry (in press). press).

Gilsson I, Mattsson M, et al. Epidemiology and treatment of post-stroke depression. Drugs Aging 